OPEN ACCESS

Edited by:

Luca Paolo Ardigò,

University of Verona, Italy

Reviewed by:

Johnny Padulo,

University of Milan, Italy

Luca Russo,

University of L'Aquila, Italy

*Correspondence:

Lin Wang

wanglin@sus.edu.cn

tThese authors share first authorship

Specialty section: This article was submitted to

Exercise Physiology, a section of the journal

Frontiers in Physiology

Received: 05 September 2020 Accepted: 27 October 2020

Published: 11 November 2020

Citation:

Wei Z, Wang $X$-X and Wang L (2020)

Effect of Short-Term Kinesiology

Taping on Knee Proprioception and

Quadriceps Performance in Healthy

Individuals.

Front. Physiol. 11:603193.

doi: 10.3389/fphys.2020.603193

\section{Effect of Short-Term Kinesiology Taping on Knee Proprioception and Quadriceps Performance in Healthy Individuals}

\author{
Zhen Wei ${ }^{1+}$, Xiao-Xi Wang ${ }^{2 \dagger}$ and Lin Wang ${ }^{1 *}$ \\ ${ }^{1}$ School of Kinesiology, Shanghai University of Sport, Shanghai, China, ${ }^{2}$ Tangshan People's Hospital, Tangshan, China
}

Background: Kinesiology taping (KT) is well known measure for preventing musculoskeletal injuries. Our study aims to explore the actual effects of KT on healthy participants' knee proprioception and quadriceps performance within $1 \mathrm{~h}$.

Methods: A total of 35 healthy male amateur runners were recruited in our study. Four taping sequences were randomly allocated to four different weeks, namely, no taping, placebo taping, KT with tension, and KT with no tension. A CON-TREX isokinetic dynamometer was used in assessing the participants' knee proprioception and muscle strength of knee extension and flexion at $60 \%$ s. The electromyography (EMG) signals of medial oblique muscle and vastus lateralis were collected using Myon EMG system synchronously. Two-way repeated measures ANOVA was used in exploring the difference between taping and time effects, and the significance was set to alpha $<0.05$.

Results: Significant interaction effect was found between the taping groups and time effect $\left[F(3.32)=2.389, p=0.029, \eta^{2}=0.050\right]$ in the peak torque during the concentric contraction of quadriceps. No significant interaction and no significant differences between groups and time effects in knee proprioception and muscle activation.

Conclusion: The effect of KT seems insufficiently large to impose a positive effect on healthy people within short periods. Health participants may not necessarily use KT to increase muscle activation and proprioception of knee.

Keywords: short-term, kinesiology taping, knee proprioception, muscle strength, muscle activation

\section{INTRODUCTION}

Kinesiology taping (KT), an elastic, water-resistant, and air permeable tape, was developed by Kenzo Kase in the 1970s, the tape can stretch to $120-140 \%$ of its original length and can recoil after application (Kase et al., 2003). On the basis of its special features, the compressive and shear force applied by the tape on the skin activates cutaneous mechanoreceptors related to joint position, movement, and force (Kase et al., 2003), conveying more information from the knee joint to the central nervous system for integration and, therefore, resulting in enhanced proprioception (Riemann and Lephart, 2002; Liu et al., 2019). Previous studies verified that the recoiling force direction of the tape is the same as that of a muscle contraction, is 
potentially transmitted to the fascia and facilitates a target muscle's production of high force (Kuo and Huang, 2013; Yam M. L. et al., 2019; Ye et al., 2019).

Knee joint proprioception and the lower extremity muscle performance play an essential role in preventing musculoskeletal injuries (Hosp et al., 2015; Pope et al., 2017). Improvement of proprioception sensitivity and quadriceps performance may reduce the risk of injuries (Oliveira et al., 2016; Bertelsen et al., 2017; Pope et al., 2017). Given the popularity of KT among sports enthusiasts, numerous studies demonstrated that KT can improve knee proprioception (Hosp et al., 2015) and activate the quadriceps (Liu et al., 2019). However, the proposed effect of KT was not found in some studies (Fernandes de Jesus et al., 2016; Oliveira et al., 2016; Serrao et al., 2016). Poon et al. (2015) even demonstrated that KT may cause sub-optimal quadricep function (Herrington et al., 2005; Poon et al., 2015).

Most previous studies related to the $\mathrm{KT}$ explored the effect of KT after 0, 24, or $48 \mathrm{~h}$ (Lins et al., 2013; Hosp et al., 2015; Lins et al., 2016; Kim et al., 2017). Given that after taping, participants may have different physical activities within $24 \mathrm{~h}$, KT may generate plastic deformations to different degrees, and the actual effect of KT may not manifest despite taping for 24 or 48 h. Additionally, common sports, such as basketball, football, and badminton, are played for $1 \mathrm{~h}$, and thus taping for a day or two cannot reflect the effect of taping for sports injury prevention. The acute influence of KT on knee neuromuscular function must be investigated. According to the contradictory results of previous work comparing KT with no taping or KT without tension, multigroup studies for exploring the short-time effects of knee taping on proprioception and quadriceps performance are limited.

Seeing that running activity is common in competitive sports, running-related injuries was common in the knee joint, our study included runners and performing multiple sets of comparisons to explore difference in proprioception and quadriceps performance difference after taping at 0.5 and $1 \mathrm{~h}$. We hypothesized that KT has a positive effect on knee proprioception and quadriceps performance within a short period and can act as a novel technology for preventing musculoskeletal injuries.

\section{MATERIALS AND METHODS}

\section{Participants}

A total of 35 healthy males were recruited for this study (aged, $22.5 \pm 2.6$ years; body height, $176.4 \pm 5.3 \mathrm{~cm}$; and body mass, $71.2 \pm 7.8 \mathrm{~kg})$. The sample size was estimated by $\mathrm{G} *$ Power (G*Power 3.1.9.2, Heinrich-Heine-Universität Düsseldorf, Düsseldorf, Germany ${ }^{1}$ ) based on $\alpha$ level of 0.05 , and power $(1-\beta)$ of 0.80 , and 0.15 dropout rate. The participants were all healthy people with exercise habits (running 10-15 km per week) from the local university. All of them were right-leg dominant according to their preferred leg when kicking a ball (Ghena et al., 1991). Participants with lower limb musculoskeletal injuries or other medical conditions 6 months before the study

${ }^{1}$ http://www.gpower.hhu.de/ were excluded. The participants provided informed consent before the experiments. This study was approved by the Human Ethics Committee of Shanghai University of Sport (2018073).

\section{Taping Methods}

After the height and body mass of each participant were measured, each participant sat with the hip and knee joint of the dominant limb in $90^{\circ}$ flexion. As suggested by Kase et al. (2003), the taping direction was from the proximal to the distal. Four taping sequences were randomized in a counterbalanced order: (1) no taping (NT), (2) placebo taping (PT), (3) KT with tension (KT-T), and (4) KT with no tension (KT-NT). To prevent any carryover effect (Fu et al., 2008), the total experiment for each participant lasted for 4 consecutive weeks, 1 week of washout phase was performed between each taping condition.

The taping methods of the KT-T on rectus femoris (RF), vastus medialis oblique (VMO), and vastus lateralis (VL) were as follows (Lins et al., 2013; Poon et al., 2015; Fernandes de Jesus et al., 2016): (1) from a point $10 \mathrm{~cm}$ below the anterior superior iliac spine and split in the form of " $Y$ " above the patella, finishing at tibial tuberosity (RF); (2) from the middle third of the medial thigh to the medial edge of the patella (VM); and (3) start from the greater trochanter of femur, finishing at the lateral edge of the patella (VMO). KT-T consistency with $50 \%$ tension was maintained in the muscles with the following equation, the leg length of the taping area was measured to calculate the actual length of the taping (Yam M. L. et al., 2019; Yam T. T. T. et al., 2019).

$$
\text { Actual length of tape to cut }(\mathrm{cm})=\left[\left(\frac{x-4}{1.5}\right)+4\right] \times 1.1
$$

where $x$ is the actual length of the leg, the anchor length of the $\mathrm{KT}$ was set to $4 \mathrm{~cm}$ ( $2 \mathrm{~cm}$ for the proximal and distal sites).

Taping regions of KT-NT was the same with KT-T but without any tension. For the PT condition, a $10 \mathrm{~cm} \mathrm{KT}$ without tension was used $10 \mathrm{~cm}$ below the anterior superior iliac spine and $10 \mathrm{~cm}$ upper edge of the patella (Thelen et al., 2008; Fernandes de Jesus et al., 2016).

\section{Measurement of the Knee Proprioception and Quadriceps Performance}

A CON-TREX isokinetic dynamometer (PHYSIOMED CON-TREX TP1000, Germany) was used in our study, which was reliable for assessing proprioception and isokinetic knee strength (Konig et al., 2004). The participants took the proprioception test first and then the muscle strength test after taping for $0,0.5$, and $1 \mathrm{~h}$ repeatedly. The intraclass correlation coefficients between the isokinetic muscle strength test were 0.96 reported by Vithoulka et al. (2010).

Proprioception was measured through joint position sense reproduction, and the participants were seated in the dynamometer chair, with their legs hanging freely. The rotation axis of the dominant leg was aligned with the lateral epicondyle of the femur. The moving arm was adjusted and fixed $5 \mathrm{~cm}$ above the medial malleolus according to previous studies (Dvir, 2004). Before the test, the dynamometer was calibrated 
to absolute zero, and the gravity correction factor was eliminated. Then each participant wore a blindfold and earplugs to eliminate auditory or visual inputs. The dominant leg of each participant was passively extended to a target angle $\left(30^{\circ}\right)$ from the starting position of $90^{\circ}$ flexion. During this process, they were asked to relax completely to prevent active muscle contraction. The participants memorized the target angle for $5 \mathrm{~s}$ (Hosp et al., 2015; three times) and then moved their leg back to the starting position passively. After a pause of $5 \mathrm{~s}$, the participants were requested to find the target angle positively (Cho et al., 2015). This process was repeated three consecutive times. The study parameter was the average absolute error of the three repetitions compared with the target angle.

For the assessment of the knee extensor/flexor torque, participants' back was slightly reclined and the dominant leg was stabilized at the distal femur, the pelvic and thorax regions were also secured with a belt (Vico et al., 2013). Before the test, participants would familiarized themselves with the equipment and then performed four maximum concentric and eccentric knee joint contractions at $60 \%$ s. Concentric contraction means that the knee joint started with the knee flexed at $90^{\circ}$ and then extend to knee flexion at $30^{\circ}$ positively, eccentric contraction from the knee flexion at $30-90^{\circ}$ negatively ( $\mathrm{Ng}$ and Wong, 2009; Padulo et al., 2013; Poon et al., 2015). Both contractions included one familiarization test using submaximal contractions. The torque parameters were recorded by means of the isokinetic dynamometer. Quadricep fatigue was minimized by giveing the participants $3 \mathrm{~min}$ to rest between series (Oliveira et al., 2016). Moreover, verbal encouragement was given during the test (Fernandes de Jesus et al., 2016). The time to peak torque, peak torque and average power were recorded for contractions for further data analysis, and the peak torque was normalized for body weight and expressed in percentage (PT/BW * 100).

The electromyography (EMG) signals of VMO and VL were captured synchronously using a Myon 320 wireless EMG system with 16-channel conditioning module (Myon 320, Schwarzenberg, Switzerland) during the muscle strength test, which was accurate to collect EMG activities (Yin et al., 2020). The skin was shaved and cleansed with $70 \%$ alcohol. Then, we attached a self-adhesive surface electrode with a diameter of $2 \mathrm{~cm}$ on the longitudinal axis of the muscle belly according to the European recommendations of Hermens et al. (2000). The sampling frequency was configured at $2000 \mathrm{~Hz}$, and the signal was filtered between 20 and $500 \mathrm{~Hz}$ and then preprocessed using a full-wave rectifier. The root mean square (RMS) approach was used at a window size of $100 \mathrm{~ms}$. The EMG device was connected to a laptop, which received the signal and stored in a file. Pro-EMG software was used for the digital analysis of the signals. For the normalization of RMS values, the participants were tasked to perform two maximum voluntary isometric contractions (MVIC) when their knees were at $60^{\circ}$ flexion for $5 \mathrm{~s}$; they were asked to rest every $1 \mathrm{~min}$ (Burden, 2010).

\section{Statistical Analysis}

All data are presented as mean and standard deviation (SD). The Kolmogorov-Smirnov test was used to test the normal distribution. Two-way repeated ANOVA was used in exploring the differences in interaction and main effects between the taping groups over time. Statistical significance was set at alpha $<0.05$. Bonferroni post hoc tests were conducted to compare specific differences. All statistics were performed using SPSS 22 (IBM, Armonk, NY, United States).

\section{RESULTS}

With regard to knee joint proprioception, no significant interaction effect was found between the taping and short-time effect groups (Figure 1). Post hoc analysis revealed that the four taping methods produced similar absolute errors within $0,0.5$, and $1 \mathrm{~h}(p=0.288)$.

We only found a significant interaction effect between the taping and time effect groups $[F(3.32)=2.389, p=0.029$, $\left.\eta^{2}=0.050\right]$ in peak torque during the concentric contraction of the quadriceps (Table 1), but Post hoc analysis showed no difference among the taping methods within short periods. No significant interaction effect was found for the time to peak torque $(p=0.363)$ and average power $(p=0.091)$ during the concentric contraction of the quadriceps.

Under the eccentric contraction of the quadriceps, the time to peak torque $(p=0.711)$, peak torque $(p=0.697)$, and average power $(p=0.533)$ parameters were similar between taping and time effects (Table 1). Post hoc analysis showed no significant difference among the four taping methods within 0.5 and $1 \mathrm{~h}$.

None of the VMO and VL muscle activities during the concentric and eccentric contraction analyzed showed significant intergroup or intragroup differences (Figure 2).

\section{DISCUSSION}

The present study provides an intuitive way of investigating the actual effect of KT on knee joints within short periods.

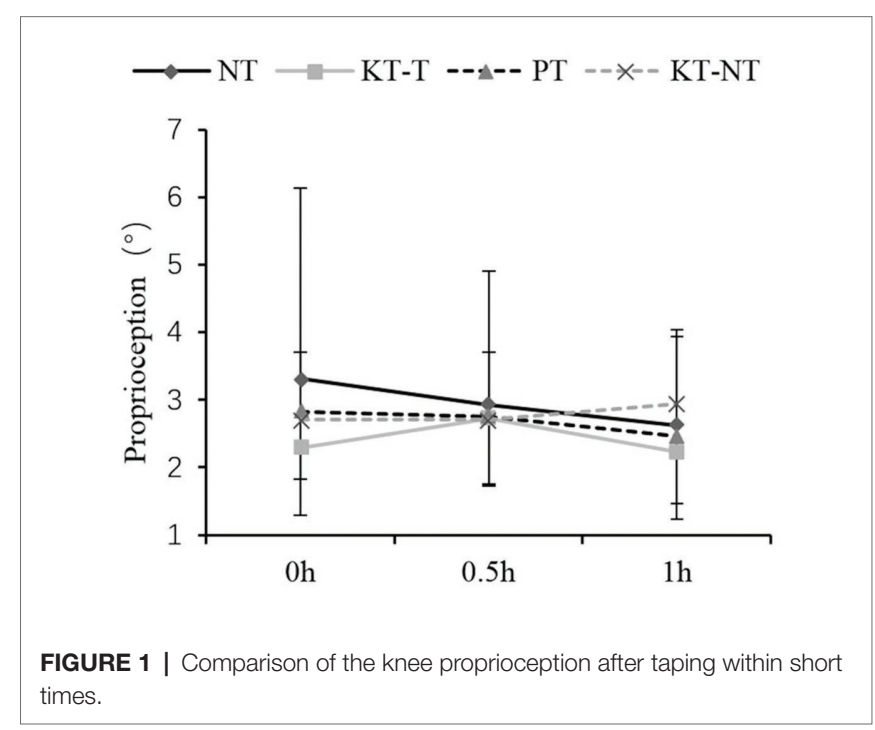


TABLE 1 | Comparison of the muscle strength after taping within short times.

\begin{tabular}{|c|c|c|c|c|c|c|c|c|c|}
\hline & & & NT & KT-T & PT & KT-NT & $F$ & $P$ & $\eta^{2}$ \\
\hline \multirow[t]{9}{*}{ Concentric } & TPT (s) & $\mathrm{Oh}$ & $0.49 \pm 0.15$ & $0.49 \pm 0.13$ & $0.48 \pm 0.11$ & $0.47 \pm 0.13$ & 1.018 & 0.363 & 0.007 \\
\hline & & $0.5 \mathrm{~h}$ & $0.52 \pm 0.15$ & $0.48 \pm 0.12$ & $0.47 \pm 0.13$ & $0.48 \pm 0.12$ & 1.113 & 0.355 & 0.024 \\
\hline & & $1 \mathrm{~h}$ & $0.48 \pm 0.12$ & $0.47 \pm 0.15$ & $0.48 \pm 0.14$ & $0.47 \pm 0.13$ & 0.183 & 0.908 & 0.004 \\
\hline & PT (N*m) & $\mathrm{Oh}$ & $2.09 \pm 0.54$ & $2.21 \pm 0.54$ & $2.16 \pm 0.51$ & $2.17 \pm 0.49$ & 2.389 & $0.029^{*}$ & 0.050 \\
\hline & & $0.5 \mathrm{~h}$ & $2.07 \pm 0.49$ & $2.21 \pm 0.55$ & $2.14 \pm 0.52$ & $2.17 \pm 0.45$ & 0.180 & 0.910 & 0.004 \\
\hline & & $1 \mathrm{~h}$ & $2.25 \pm 0.50$ & $2.19 \pm 0.51$ & $2.11 \pm 0.51$ & $2.22 \pm 0.41$ & 1.863 & 0.157 & 0.014 \\
\hline & $\mathrm{AP}(\mathrm{w})$ & $\mathrm{Oh}$ & $74.07 \pm 22.66$ & $79.37 \pm 26.76$ & $79.33 \pm 27.48$ & $80.14 \pm 26.98$ & 1.840 & 0.091 & 0.039 \\
\hline & & $0.5 \mathrm{~h}$ & $74.13 \pm 23.17$ & $81.37 \pm 24.98$ & $81.10 \pm 29.76$ & $79.19 \pm 28.19$ & 0.167 & 0.919 & 0.004 \\
\hline & & $1 \mathrm{~h}$ & $82.35 \pm 26.96$ & $80.26 \pm 22.74$ & $80.76 \pm 28.44$ & $80.76 \pm 24.64$ & 2.806 & 0.062 & 0.020 \\
\hline \multirow[t]{9}{*}{ Eccentric } & TPT (s) & $\mathrm{Oh}$ & $0.48 \pm 0.12$ & $0.49 \pm 0.12$ & $0.50 \pm 0.09$ & $0.48 \pm 0.13$ & 0.623 & 0.711 & 0.014 \\
\hline & & $0.5 \mathrm{~h}$ & $0.48 \pm 0.11$ & $0.50 \pm 0.12$ & $0.49 \pm 0.12$ & $0.50 \pm 0.12$ & 0.094 & 0.963 & 0.002 \\
\hline & & $1 \mathrm{~h}$ & $0.50 \pm 0.11$ & $0.50 \pm 0.13$ & $0.51 \pm 0.12$ & $0.48 \pm 0.13$ & 0.685 & 0.505 & 0.005 \\
\hline & $\mathrm{PT}\left(\mathrm{N}^{*} \mathrm{~m}\right)$ & $\mathrm{Oh}$ & $2.43 \pm 0.60$ & $2.44 \pm 0.65$ & $2.42 \pm 0.58$ & $2.40 \pm 0.66$ & 0.641 & 0.697 & 0.014 \\
\hline & & $0.5 \mathrm{~h}$ & $2.45 \pm 0.61$ & $2.51 \pm 0.59$ & $2.50 \pm 0.62$ & $2.43 \pm 0.68$ & 0.040 & 0.989 & 0.001 \\
\hline & & $1 \mathrm{~h}$ & $2.50 \pm 0.62$ & $2.44 \pm 0.57$ & $2.41 \pm 0.50$ & $2.44 \pm 0.56$ & 1.359 & 0.259 & 0.010 \\
\hline & $\mathrm{AP}(\mathrm{w})$ & $\mathrm{Oh}$ & $91.41 \pm 22.87$ & $92.80 \pm 25.55$ & $93.39 \pm 21.36$ & $90.51 \pm 27.64$ & 0.849 & 0.533 & 0.018 \\
\hline & & $0.5 \mathrm{~h}$ & $93.85 \pm 24.06$ & $95.08 \pm 19.87$ & $92.05 \pm 20.35$ & $91.89 \pm 26.25$ & 0.073 & 0.974 & 0.002 \\
\hline & & $1 \mathrm{~h}$ & $2.50 \pm 0.62$ & $2.44 \pm 0.57$ & $2.41 \pm 0.50$ & $2.44 \pm 0.56$ & 0.857 & 0.425 & 0.006 \\
\hline
\end{tabular}

Values are means \pm standard deviation (SD); significant differences ( $\left.{ }^{*} p<0.05\right)$ are highlighted in bold for interaction effect, taping effect, and time effect from the top for different parameters. TPT, time to peak torque; PT, peak torque; and AP, average power.
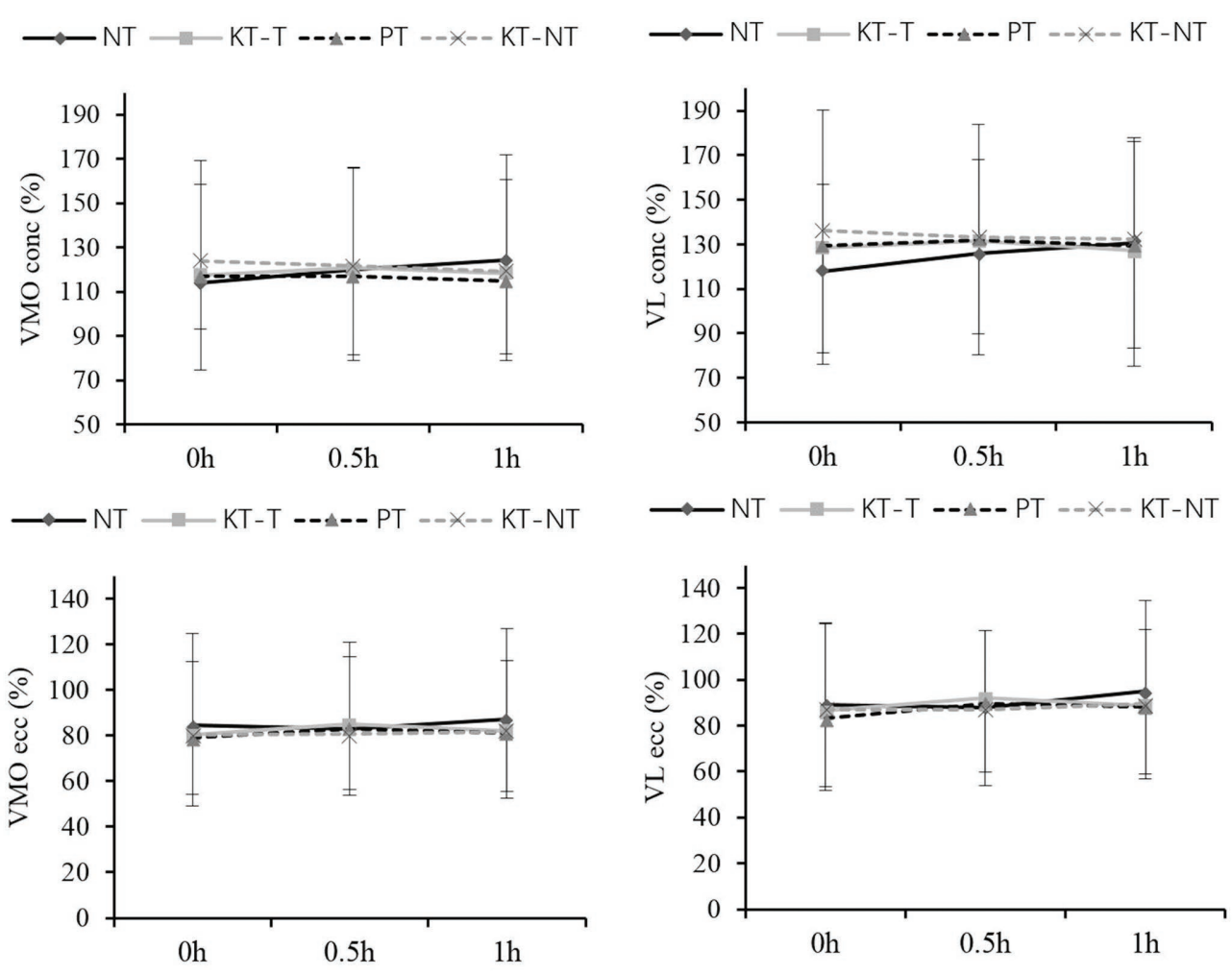

FIGURE 2 | Comparison of the electromyography (EMG) activities of vastus medialis oblique (VMO) and vastus lateralis (VL) after taping within short times. Means and standard deviations of the variables: normalized root mean square (RMS) of the VMO and VL during concentric (conc) and eccentric (ecc) contraction.

The results reveal that the knee proprioception and muscle activation cannot be improved by the application of KT. Data from our research may guide health individuals in using KT to prevent knee injuries during exercises.
Shortly after taping, no significant difference on knee proprioception was found among the four taping groups, indicating that KT cannot improve knee proprioception in health people. This result is supported by the results of previous 
studies that explored knee joint position sense in healthy subject after taping for $24 \mathrm{~h}$ (Torres et al., 2016). However, Liu et al. (2019) established that KT can improve the knee proprioception of patients with anterior cruciate ligament (ACL) injury. Cho et al. (2015) found that KT potentially improves positive knee joint position sense in patients with knee osteoarthritis after $1 \mathrm{~h}$. Callaghan et al. (2008) showed that the poor proprioception of patients with patellofemoral pain syndrome can be improved after taping. For people with knee ACL injury (Barrack et al., 1994), knee osteoarthritic (Barrett, 1991) or knee with chronic effusions (Wingfield, 2013; Achenbach et al., 2017), injury history may be contributed to knee position sense receptor deficiency even after recovery. Poor proprioception may be more sensitive to and easier to facilitate with KT and transfer more proprioceptive information from the joint structures to the nervous system. Therefore, patients with poor proprioception tend to receive more benefits than healthy participants with good proprioception (Callaghan et al., 2002; Hosp et al., 2015). As a result, healthy knee joints may not require KT to prevent knee injuries during competitions, but its use by people with knee injuries history is reasonable. This hypothesis requires further investigation because of insufficient high-quality research exploring the effect of KT under different sports durations.

Muscle strength did not change within $1 \mathrm{~h}$, indicating that the pulling force that was transmitted to the fascia and facilitated the target muscle cannot impose any obvious effect on healthy people. Furthermore, the elasticity of the KT may gradually decrease and even persist for a long time but cannot impose any effect on knee joint. The results are partly identical with those of Melo et al. (2018) and Lins et al. (2016), who showed that KT cannot alter muscle strength during the knee extension process after taping for 0 or $72 \mathrm{~h}$ compared with NT. Given that the studies in the current literature mainly explored the effect of KT within 24 or $48 \mathrm{~h}$, the short time effects of KT should be studied specifically.

A significant interaction effect on peak torque during the concentric contraction was found, but muscle strength was the same in the four taping groups within short periods, indicating that the recoil force of KT cannot increase muscle strength. This result was partly supported by a recent study of Yeung and Yeung (2016), who explored the excitability of the quadriceps' motor neurons by comparing the latency time of the knee-jerk reflex and proposed that KT can produce force for the quadriceps, although they reported that the effect is not enough to alter muscle contraction strength. Additionally, the positive interaction effect may be related to psychological comfort (Donec and Kubilius, 2020). Poon et al. (2015) included a placebo group to explore the psychological comfort of KT and demonstrated that KT cannot improve the muscle strength and EMG activity of quadriceps during an isokinetic muscle strength test and even suspected that the positive results reported by previous studies may be attributed to psychological effects. Although the PT group in our studies was similar to the KT group, we still speculated that psychological factors play an important role in taping, but the underlying physiological mechanisms were not fully clarified.

In the current study, no significant change in the eccentric contraction of quadriceps was observed. Although Vithoulka et al. (2010) demonstrated that the pulling force generated by
KT can facilitate the fascia and plays an important role in the mechanical transmission of muscle eccentric contraction. Our results and those of Oliveira et al. (2016) suggested that the potential effect generated by KT cannot produce a positive effect within short periods or even within $24 \mathrm{~h}$. The discrepancy may be partially explained by psychological comfort, as shown by the results of Yeung and Yeung (2016).

With respect to EMG activity, even though the theories indicated that $\mathrm{KT}$ can activate skin receptors and improve neuromuscular recruitment, our study revealed no significant taping or time differences. VMO and VL activity did not change after taping for 0.5 or $1 \mathrm{~h}$. The finding partly supports the results of previous studies where no significant difference was observed after taping 24 or 48 h (Lins et al., 2016). This study also supported other recent studies indicating that the stimulation of KT cannot activate quadricep activity (Lins et al., 2013; Oliveira et al., 2016; Serrao et al., 2016; Melo et al., 2018). However, our findings contradicted the data presented by Watanabe et al. (Herrington et al., 2005; Watanabe, 2019), who proposed that the surface EMG amplitude of the VL muscle decreased and the application of a tape may decrease the neuromuscular activation of the knee extensor muscles in healthy runners. Moreover, the inhibited effect of patellar taping was also verified in patients with patellofemoral pain syndrome by $\mathrm{Ng}$ and Wong (2009), who found that VMO and VL activities in patients with knee injuries significantly decrease after patella taping and concluded that knee taping may cause the joint to function sub-optimally. Therefore, the current study and previous data suggest that taping cannot produce a positive effect on knee joint through the activation of muscle activity, which may be inhibited as in the case of patellar taping.

A limitation of the present study was that the results can only represent the effect of KT on healthy peoples' knee proprioception and muscle performance. The actual effect of KT on sports enthusiasts with knee injury history requires further study.

\section{CONCLUSION}

In the current study, subtle stimulation produced by KT may not cause a measurable change in function in healthy participants within short periods. Therefore, compared with individuals with knee history, healthy sports enthusiasts may cautiously use KT to improve their neuromuscular function.

\section{DATA AVAILABILITY STATEMENT}

The original contributions presented in the study are included in the article/supplementary material, and further inquiries can be directed to the corresponding author.

\section{ETHICS STATEMENT}

The studies involving human participants were reviewed and approved by Human Ethics Committee of Shanghai University 
of Sport (2018073). The patients/participants provided their written informed consent to participate in this study.

\section{AUTHOR CONTRIBUTIONS}

ZW recruited the subjects, collected the data, and wrote the manuscript. X-XW and LW conceived the study, undertook statistical analysis, and interpreted the results. All authors contributed to the article and approved the submitted version.

\section{REFERENCES}

Achenbach, L., Krutsch, V., Weber, J., Nerlich, M., Luig, P., Loose, O., et al. (2017). Neuromuscular exercises prevent severe knee injury in adolescent team handball players. Knee Surg. Sports Traumatol. Arthrosc. 26, 1901-1908. doi: $10.1007 /$ s00167-017-4758-5

Barrack, R. L., Lund, P. J., and Skinner, H. B. (1994). Knee joint proprioception revisited. J. Sport Rehabil. 3, 18-42. doi: 10.1123/jsr.3.1.18

Barrett, D. (1991). Joint proprioception in normal, osteoarthritic and replaced knees. J. Bone Joint Surg. (Br.) 73, 53-57. doi: 10.1302/0301-620X.73B1.1991775

Bertelsen, M. L., Hulme, A., Petersen, J., Brund, R. K., Sorensen, H., Finch, C. F., et al. (2017). A framework for the etiology of running-related injuries. Scand. J. Med. Sci. Sports 27, 1170-1180. doi: 10.1111/sms.12883

Burden, A. (2010). How should we normalize electromyograms obtained from healthy participants? What we have learned from over 25 years of research. J. Electromyogr. Kinesiol. 20, 1023-1035. doi: 10.1016/j.jelekin.2010.07.004

Callaghan, M. J., Selfe, J., Bagley, P. J., and Oldham, J. A. (2002). The effects of patellar taping on knee joint proprioception. J. Athl. Train. 37, 19-24. doi: 10.1016/S0031-9406(05)61377-6

Callaghan, M. J., Selfe, J., McHenry, A., and Oldham, J. A. (2008). Effects of patellar taping on knee joint proprioception in patients with patellofemoral pain syndrome. Man. Ther. 13, 192-199. doi: 10.1016/j.math.2006.11.004

Cho, H., Kim, E., Kim, J., and Yoon, Y. (2015). Kinesio taping improves pain, range of motion, and proprioception in older patients with knee osteoarthritis: a randomized controlled trial. Am. J. Phys. Med. Rehabil. 94, 192-200. doi: 10.1097/PHM.0000000000000148

Donec, V., and Kubilius, R. (2020). The effectiveness of Kinesio Taping $\left({ }^{\circledR}\right)$ for mobility and functioning improvement in knee osteoarthritis: a randomized, double-blind, controlled trial. Clin. Rehabil. 34, 877-889. doi: 10.1177/0269215520916859

Dvir, Z. (2004). Isokinetics muscle testing, interpretation and clinical applications. 2nd Edn. UK: Churchill Livingstone.

Fernandes de Jesus, J., de Almeida Novello, A., Bezerra Nakaoka, G., Curcio Dos Reis, A., Fukuda, T. Y., and Fernandes Bryk, F. (2016). Kinesio taping effect on quadriceps strength and lower limb function of healthy individuals: a blinded, controlled, randomized, clinical trial. Phys. Ther. Sport 18, 27-31. doi: 10.1016/j.ptsp.2015.11.004

Fu, T. C., Wong, A. M., Pei, Y. C., Wu, K. P., Chou, S. W., and Lin, Y. C. (2008). Effect of Kinesio taping on muscle strength in athletes-a pilot study. J. Sci. Med. Sport 11, 198-201. doi: 10.1016/j.jsams.2007.02.011

Ghena, D. R., Kurth, A. L., Thomas, M., and Mayhew, J. (1991). Torque characteristics of the quadriceps and hamstring muscles during concentric and eccentric loading. J. Orthop. Sports Phys. Ther. 14, 149-154. doi: 10.2519/ jospt.1991.14.4.149

Hermens, H. J., Freriks, B., Disselhorst-Klug, C., and Rau, G. (2000). Development of recommendations for SEMG sensors and sensor placement procedures. J. Electromyogr. Kinesiol. 10, 361-374. doi: 10.1016/s1050-6411(00)00027-4

Herrington, L., Malloy, S., and Richards, J. (2005). The effect of patella taping on vastus medialis oblique and vastus laterialis EMG activity and knee kinematic variables during stair descent. J. Electromyogr. Kinesiol. 15, 604-607. doi: 10.1016/j.jelekin.2005.05.002

Hosp, S., Bottoni, G., Heinrich, D., Kofler, P., Hasler, M., and Nachbauer, W. (2015). A pilot study of the effect of Kinesiology tape on knee proprioception after physical activity in healthy women. J. Sci. Med. Sport 18, 709-713. doi: $10.1016 /$ j.jsams.2014.09.004

\section{FUNDING}

This study was funded by the National Natural Science Fund of China (11572202, 11772201, and 31700815).

\section{ACKNOWLEDGMENTS}

The authors are thankful for all the subjects' voluntary contribution during the completion of this study.

Kase, K., Wallis, J., and Kase, T. (2003). Clinical therapeutic applications of Kinesio taping method. 2nd Edn. Tokyo, Japan: Ken Ikai Co Ltd.

Kim, K. M., Davis, B., Hertel, J., and Hart, J. (2017). Effects of Kinesio taping in patients with quadriceps inhibition: a randomized, single-blinded study. Phys. Ther. Sport 24, 67-73. doi: 10.1016/j.ptsp.2016.08.015

Konig, T., Baur, H., Muller, S., and Mayer, F. (2004). "Reproducibility of isokinetic peak torque in the knee and ankle joint" in Isokinetics and Exercise Science; January 01, 2004.

Kuo, Y. L., and Huang, Y. C. (2013). Effects of the application direction of Kinesio taping on isometric muscle strength of the wrist and fingers of healthy adults-a pilot study. J. Phys. Ther. Sci. 25, 287-291. doi: 10.1589/jpts.25.287

Lins, C. A., Borges, D. T., Macedo, L. B., Costa, K. S., and Brasileiro, J. S. (2016). Delayed effect of Kinesio taping on neuromuscular performance, balance, and lower limb function in healthy individuals: a randomized controlled trial. Braz. J. Phys. Ther. 20, 231-239. doi: 10.1590/bjpt-rbf.2014.0161

Lins, C. A., Neto, F. L., Amorim, A. B., Macedo Lde, B., and Brasileiro, J. S. (2013). Kinesio Taping(R) does not alter neuromuscular performance of femoral quadriceps or lower limb function in healthy subjects: randomized, blind, controlled, clinical trial. Man. Ther. 18, 41-45. doi: 10.1016/j.math.2012.06.009

Liu, K., Qian, J., Gao, Q., and Ruan, B. (2019). Effects of Kinesio taping of the knee on proprioception, balance, and functional performance in patients with anterior cruciate ligament rupture: a retrospective case series. Medicine 98:e17956. doi: 10.1097/md.0000000000017956

Melo, S. A., Macedo, L. B., Borges, D. T., and Brasileiro, J. S. (2018). Effects of kinesio taping on neuromuscular performance and pain of individuals affected by patellofemoral pain: a randomized controlled trial. Physiother. Theory Pract. 36, 1-11. doi: 10.1080/09593985.2018.1492657

Ng, G. Y., and Wong, P. Y. (2009). Patellar taping affects vastus medialis obliquus activation in subjects with patellofemoral pain before and after quadriceps muscle fatigue. Clin. Rehabil. 23, 705-713. doi: 10.1177/0269215509334835

Oliveira, A. K., Borges, D. T., Lins, C. A., Cavalcanti, R. L., Macedo, L. B., and Brasileiro, J. S. (2016). Immediate effects of Kinesio Taping ${ }^{\circledR}$ on neuromuscular performance of quadriceps and balance in individuals submitted to anterior cruciate ligament reconstruction: a randomized clinical trial. $J$. Sci. Med. Sport 19, 2-6. doi: 10.1016/j.jsams.2014.12.002

Padulo, J., Laffaye, G., Chamari, K., and Concu, A. (2013). Concentric and eccentric: muscle contraction or exercise? Sports Health 5:306. doi: 10.1177/ 1941738113491386

Poon, K. Y., Li, S. M., Roper, M. G., Wong, M. K., Wong, O., and Cheung, R. T. (2015). Kinesiology tape does not facilitate muscle performance: a deceptive controlled trial. Man. Ther. 20, 130-133. doi: 10.1016/j.math.2014.07.013

Pope, D., Barton, C. J., Goom, T., and Lehman, G. (2017). Infographic: recommendations for running injuries. $\mathrm{Br}$. J. Sports Med. 53, 148-149. doi: 10.1136/bjsports-2017-098049

Riemann, B. L., and Lephart, S. M. (2002). The sensorimotor system, part II: the role of proprioception in motor control and functional joint stability. J. Athl. Train. 37, 80-84.

Serrao, J. C., Mezencio, B., Claudino, J. G., Soncin, R., Miyashiro, P. L., Sousa, E. P., et al. (2016). Effect of 3 different applications of Kinesio Taping Denko ${ }^{\circledR}$ on electromyographic activity: inhibition or facilitation of the quadriceps of males during squat. Exerc. J. Sports. Sci. Med. 15, 403-409.

Thelen, M. D., Dauber, J. A., and Stoneman, P. D. (2008). The clinical efficacy of kinesio tape for shoulder pain: a randomized, double-blinded, clinical trial. J. Orthop. Sports Phys. Ther. 38, 389-395. doi: 10.2519/jospt.2008.2791 
Torres, R., Trindade, R., and Goncalves, R. S. (2016). The effect of kinesiology tape on knee proprioception in healthy subjects. J. Bodyw. Mov. Ther. 20, 857-862. doi: 10.1016/j.jbmt.2016.02.009

Vico, R. D., Ardigò, L. P., Salernitano, G., Chamari, K., and Padulo, J. (2013). The acute effect of the tongue position in the mouth on knee isokinetic test performance: a highly surprising pilot study. Muscles Ligaments Tendons J. 3, 318-323. doi: 10.11138/mltj/2013.3.4.318

Vithoulka, I., Malliou, A. B., Aggelousis, N., Karatsolis, K., and Diamantopoulos, K. (2010). The effects of Kinesio-Taping $\mathrm{R}$ on quadriceps strength during isokinetic exercise in healthy non athlete women. Isokinet. Exerc. Sci. 18, 1-6. doi: 10.3233/IES-2010-0352

Watanabe, K. (2019). Effect of taping and its conditions on electromyographic responses of knee extensor muscles. Hum. Mov. Sci. 63, 148-155. doi: 10.1016/j.humov.2018.12.003

Wingfield, K. (2013). Neuromuscular training to prevent knee injuries in adolescent female soccer players. Clin. J. Sport Med. 23, 407-408. doi: 10.1097/01.jsm.0000433153.51313.6b

Yam, T. T. T., Or, P. P. L., Ma, A. W. W., Fong, S. S. M., and Wong, M. S. (2019). Effect of Kinesio taping on Y-balance test performance and the associated leg muscle activation patterns in children with developmental coordination disorder: a randomized controlled trial. Gait Posture 68, 388-396. doi: 10.1016/j.gaitpost.2018.12.025

Yam, M. L., Yang, Z., Zee, B. C., and Chong, K. C. (2019). Effects of Kinesio tape on lower limb muscle strength, hop test, and vertical jump performances: a meta-analysis. BMC Musculoskelet. Disord. 20:212. doi: 10.1186/s12891-019-2564-6

Ye, W., Jia, C., Jiang, J., Liang, Q., and He, C. (2019). Effectiveness of elastic taping in patients with knee osteoarthritis: a systematic review and meta-analysis. Am. J. Phys. Med. Rehabil. 99, 495-503. doi: 10.1097/ phm.0000000000001361

Yeung, S. S., and Yeung, E. W. (2016). Acute effects of Kinesio taping on knee extensor peak torque and stretch reflex in healthy adults. Medicine 95:e2615. doi: 10.1097/md.0000000000002615

Yin, L., Lai, Z., Hu, X., Liu, K., and Wang, L. (2020). Evaluating postural control and lower-extremity muscle activation in individuals with chronic ankle instability. J. Vis. Exp. 163:e61592. doi: 10.3791/61592

Conflict of Interest: The authors declare that the research was conducted in the absence of any commercial or financial relationships that could be construed as a potential conflict of interest.

Copyright (c) 2020 Wei, Wang and Wang. This is an open-access article distributed under the terms of the Creative Commons Attribution License (CC BY). The use, distribution or reproduction in other forums is permitted, provided the original author(s) and the copyright owner(s) are credited and that the original publication in this journal is cited, in accordance with accepted academic practice. No use, distribution or reproduction is permitted which does not comply with these terms. 